\title{
KOMUNIKASIRINGKAS
}

\section{PENGARUH PENGKAYAAN ROTIFERA (Brachionus sp.) DENGAN MINYAKIKAN DAN MINYAK JAGUNG TERHADAP PERTUMBUHAN DAN SINTASAN LARVA IKAN BETUTU (Oxyeleotris marmorata Blkr.)}

\author{
Evi Tahapari"), Agus Priyadi", dan Retna Utami")
}

\begin{abstract}
ABSTRAK
Penelitian pengkayaan rotifera (Brachionus sp.) untuk pakan larva ikan betutu (Oxyeleotris marmorata) telah dilaksanakan di Balai Penelitian Perikanan Air Tawar, Sukamandi pada bulan Agustus sampai dengan November 1997. Tujuan penelitian adalah untuk mengetahui pengaruh berbagai jenis pengkayaan rotifera (Brachionus sp.) sebagai pakan larva ikan betutu terhadap pertumbuhan dan sintasannya. Perlakuan adalah jenis pengkayaan rotifera dengan : klorella; klorella + minyak ikan; klorella + minyak jagung; dan klorella + minyak ikan + minyak jagung dimana setiap perlakuan diulang sebanyak tiga kali. Ikan uji adalah larva umur tiga hari dari hasil pemijahan secara alami. Wadah ikan uji adalah 12 buah akuarium, masing-masing diisi $20 \mathrm{~L}$ air. Larva dipelihara dengan padat tebar 25 ekor/L selama 14 hari. Rotifera hasil pengkayaan diberikan sebagai pakan larva ikan dengan frekuensi pemberian sebanyak tiga kali/hari. Hasil penelitian menunjukkan bahwa larva yang diberi rotifera hasil pengkayaan dengan klorella +minyak ikan dan klorella + minyak ikan + minyak jagung memberikan pertumbuhan bobot relatif yang terbaik dibandingkan dengan perlakuan pengkayaan dengan klorella dan perlakuan pengkayaan dengan klorella + minyak jagung. Keempat jenis pengkayaan tidak memberikan perbedaan pengaruh yang nyata terhadap sintasan dan pertumbuhan panjang relatif larva selama percobaan.
\end{abstract}

ABSTRACT: Effect of the enrichment of rotifers (Brachionus sp.) with fish oil and corn oil on growth and survival rate of the sand goby (Oxyeleotris marmorata BIkr.) Iarvae. By : Evi Tahapari, Agus Priyadi, and Retna Utami

The experiment of the enrichment of rotifers (Brachionus sp.) for sand goby (Oxyeleotris marmorata Blkr.) larvae was done in the Research Institute Freshwater Fisheries (RIFF), Sukamandi on August to November, 1997. The aim was to density the influence of various kinds of enrichment of rotifers (Brachionus sp.), as the feed of larvae to fish growth and survival. Treatments applied were the kinds of rotifers enrichment using : Chlorella; Chlorella + fish oil; Chlorella + Corn oil and Chlorella + fish oil + corn oil; replicated three times. Experiment fish were larvae of three-day old. resulted from natural spawning. They were reared in 12 aquaria, each was filled with $20 \mathrm{~L}$ of water. The density was 25 ind. $/$. The feed were given the feed three times daily. The result of experiment showed that the larvae given enriched rotifers of chlorella + fish oil and chlorella + fish oil + corn oil gained relatively better growth than those given enriched rotifers of chlorella only and of chlorella + corn oil. The kinds of enrichment of the four treatments did not give any different effect on the survival and the growth of sand goby larvae.

KEYWORDS: enrichment, rotifer, larvae, sand goby

\section{PENDAHULUAN}

Ikan betutu termasuk jenis ikan karnivora dan merupakan salah satu komoditas ekspor ikan air tawar. Sampai saat ini ikan betutu (Oxyeleotris marmorata Blkr.) dihasilkan dari tangkapan di perairan umum, baik ukuran benih maupun ukuran konsumsi, sehingga budi daya ikan betutu sulit berkembang. Permasalahan yang sering dihadapi dalam perbenihan ikan betutu adalah masih tingginya tingkat kematian larva terutama pada fase perkembangannya. Larva betutu yang dipelihara dengan pemberian pakan naupli copepoda hanya dapat hidup sampai hari ke delapan saja (Tan \& Lam, 1973), demikian pula dengan larva betutu yang diberi pakan rotifera dan dipelihara dalam akuarium bervolume $30 \mathrm{~L}$ mati total pada hari ke-12 (Widiyati \& Djajasewaka, 1992). Sintasan larva yang masih rendah diduga akibat larva tidak mendapatkan pakan yang tepat pada saat larva harus mengambil pakan dari luar dan larva sangat peka terhadap lingkungan hidupnya (Faradia, 1991). Untuk mengatasi hal tersebut, perlu dicari teknologi

-) Peneliti pada Balai Penelitian Perikanan Air Tawar Sukamandi 
pemeliharaan larva yang tepat, antara lain melalui penyediaan pakan alami yang mempunyai nilai nutrisi tinggi. Perlakuan pengkayaan pada rotifera sebagai pakan larva betutu diduga dapat meningkatkan kualitas nutrisinya, terutama peningkatan kandungan asam lemak essensialnya. Ikan memerlukan asam lemak essensial tertentu, lemak yang berasal dari tumbuhtumbuhan berbeda komposisi asam-asam lemaknya dengan lemak yang berasal dari hewan. Berdasarkan hal tersebut dilakukan penelitian pengkayaan rotifera melalui penambahan minyak jagung, minyak ikan dan campuran keduanya untuk pakan larva ikan betutu.

\section{BAHAN DAN METODE}

Penelitian ini dilakukan di Laboratorium Balai Penelitian Perikanan Air Tawar, Sukamandi, berlangsung selama 4 bulan mulai dari bulan Agustus sampai November 1997. Tahapan dari penelitian diawali dengan persiapan bahan dan wadah yang akan digunakan sebagai media untuk kultur klorella dan rotifera secara murni dan massal. Kemudian rotifera yang tersedia yang akan diberikan sebagai perlakuan pakan larva betutu diperkaya terlebih dahulu dengan bahan-bahan sebagai berikut:

A. klorella

B. klorella + ragi roti + minyak ikan

C. klorella + ragi roti + minyak jagung

D. klorella + ragi roti + minyak ikan + minyak jagung

Dosis campuran untuk pengkayaan adalah sebagai berikut : klorella $40 \mathrm{~L}$ dengan kepadatan 0,7 - 1,5 x $10^{6} \mathrm{sel} / \mathrm{mL}$, ragi roti $12 \mathrm{~g}$, Minyak $5 \mathrm{~mL}$. Setelah rotifera diperkaya selama 2-4 jam sambil diaerasi, kemudian diberikan pada larva yang berumur 4 hari, hal ini berdasarkan pertimbangan bahwa kuning telur yang terkandung dalam larva mulai habis pada hari ke-5. Pakan hasil pengkayaan tersebut terlebih dahulu dicuci untuk menghilangkan sisa minyak. Rotifera diberikan dengan kepadatan 50-100 ind./mL.

Ikan uji yang digunakan dalam penelitian adalah larva ikan betutu yang berumur 3 hari yang diperoleh dari penetasan alami. Wadah ikan uji yang digunakan adalah akuarium dengan ukuran $60 \times 30 \times 40 \mathrm{~cm}^{3}$ sebanyak 12 buah yang dilengkapi dengan aerasi dan heater yang diset pada suhu $28^{\circ} \mathrm{C}-30^{\circ} \mathrm{C}$. Padat tebar ikan uji yang digunakan dalam setiap akuarium adalah 25 ekor/L. Frekuensi pemberian pakan 3 kali sehari. Pengukuran panjang dan bobot larva dilakukan pada awal dan akhir percobaan. Panjang diukur dengan menggunakan mikrometer okuler dan bobot diukur dengan menggunakan timbangan analitik dengan tingkat ketelitian $0,0001 \mathrm{~g}$. Untuk pertumbuhan relatif larva dihitung dengan menggunakan rumus yang dikemukakan oleh Effendi (1978) sebagai berikut :

$$
H=\frac{\text { Lt }- \text { Lo }}{\text { Lo }}
$$

$\mathrm{H}=$ = Pertumbuhan panjang relatif

Lt = Panjang ikan pada waktu $\mathrm{t}(\mathrm{mm})$

Lo = Panjang ikan pada awal $\operatorname{percobaan}(\mathrm{mm})$

$$
W=\frac{W t-W a}{W o}
$$

$\mathrm{W}$ = Pertambahan bobot relatif

$\mathrm{Wt}=$ Bobot ikan pada waktu $\mathrm{t}(\mathrm{mg})$

Wo = Bobot ikan pada awal percobaan (mg)

Sintasan dihitung berdasarkan rumus yang dikemukakan oleh Effendi (1978) sebagai berikut :

$$
\mathrm{S}=\frac{\mathrm{Nt}}{\mathrm{No}} \times 100 \%
$$

$\mathrm{S}=$ Sintasan

No = Jumlah larva pada awal penelitian

Nt = Jumlah larva yang hidup pada akhir penelitian

\section{HASIL DAN BAHASAN}

Hasil pengamatan pengaruh berbagai jenis pengkayaan rotifera terhadap pertumbuhan dan sintasan larva ikan betutu disajikan pada Tabel 1. Hasil analisis ragam untuk sintasan dan pertumbuhan relatif panjang larva betutu selama penelitian pada keempat perlakuan tidak berbeda nyata $(P>0,05)$. Sintasan larva pada penelitian ini selama empat belas hari penelitian berkisar antara $1,2 \%-7,6 \%$. Rendahnya tingkat sintasan larva betutu telah dilaporkan oleh Tavarutmaneegul \& Lin (1988), bahwa dengan pemberian pakan rotifera di kolam, sintasannya $7 \%$ $55 \%$ selama 12 hari pemeliharaan, kemudian Widiyati \& Djajasewaka (1992) melaporkan sintasan larva sampai umur 14 hari sangat rendah yaitu $0 \%-6,98 \%$.

Rendahnya tingkat sintasan larva diduga selain karena kualitas rotifera yang diberikan pada larva ikan betutu masih belum sesuai untuk pertumbuhan optimal, juga diduga adanya faktor lain yang belum diketahui penyebabnya, misalnya kondisi lingkungan seperti kedalaman, cahaya, bentuk wadah ikan, dan sebagainya. Respon pertumbuhan (panjang dan bobot) larva ikan betutu terhadap berbagai jenis pangkayaan pada rotifera memberikan pengaruh berbeda terhadap pertambahan bobot relatif $(P<0,05)$ masing-masing perlakuan (Tabel 1). Berdasarkan hasil uji statistik menunjukkan bahwa perlakuan pengkayaan dengan klorella tidak memberikan pengaruh yang berbeda $(P>0,05)$ terhadap perlakuan pengkayaan dengan 
Tabel 1. Sintasan, pertambahan bobot relatif, dan pertambahan panjang relatif larva ikan betutu pada setiap perlakuan

Table 1. Survival rate, weight, and length gain relative of sand goby larvae on each treatment

\begin{tabular}{lccc}
\hline \multicolumn{1}{c}{$\begin{array}{c}\text { Periakuan } \\
\text { (Treatment) }\end{array}$} & $\begin{array}{c}\text { Rata-rata } \\
\text { sintasan (\%) } \\
\text { Average } \\
\text { survival rate (\%) }\end{array}$ & $\begin{array}{c}\text { Rata-rata pertambahan } \\
\text { bobot relatif (mg) } \\
\text { Average of relative } \\
\text { weight gain }(\mathrm{mg})\end{array}$ & $\begin{array}{c}\text { Rata-rata pertambahan } \\
\text { panjang relatif }(\mathrm{mm}) \\
\text { Average of relative } \\
\text { length gain }(\mathrm{mm})\end{array}$ \\
$\begin{array}{l}\text { Klorella (Chlorella) } \\
\text { Klorella + minyak ikan } \\
\text { (Chlorella + fish oil) }\end{array}$ & $3.33 \pm 1,286^{\mathrm{a}}$ & $0.86 \pm 0.158^{\mathrm{a}}$ & $0.22 \pm 0.025^{\mathrm{a}}$ \\
$\begin{array}{l}\text { Klorella + minyak jagung } \\
\text { Clorella + com oil } \\
\text { Klorella + minyak ikan + } \\
\text { minyak jagung } \\
\text { clorella + fish oil + com oil }\end{array}$ & $5.86 \pm 1,617^{\mathrm{a}}$ & $1.76 \pm 0.319^{\mathrm{b}}$ & $0.24 \pm 0.056^{\mathrm{a}}$ \\
\hline
\end{tabular}

Catatan/Note: Nilai dalam kolom ù diikuti huruf superskrip ù sama tidak berbeda nyata (values in column followed with same superscript are not significantly different $)(P<0.05)$

klorella + minyak jagung, tetapi memberikan pengaruh yang berbeda $(P<0,05)$ terhadap perlakuan pengkayaan dengan klorella + minyak ikan dan perlakuan pengkayaan dengan klorella + minyak ikan + minyak jagung. Kompiang \& llyas (1988) menyatakan kekurangan asam lemak essensial dalam makanan akan menyebabkan pertumbuhan yang rendah, menurunnya efisiensi ransum dan dapat meningkatkan angka kematian larva ikan. Kematian larva ikan tinggi pada periode setelah kuning telur habis dan pertama kali makan mungkin disebabkan ransum yang dipasok kekurangan asam lemak dekosaheksaenoat $(22: 6 w 3)$ dan asam lemak eikosapentaenoat (20:5w3) di dalam HUFA (Kitajama et al., 1980; Koren et al., 1989).

Kemudian Petriel et al. (1984) dalam Chuang (1990) melaporkan bahwa udang argentina, Artemesia longinaris dengan pakan yang ditambah minyak ikan menghasilkan tingkat sintasan $87,3 \%$; kemudian dengan penambahan minyak nabati memberikan tingkat sintasan $53,3 \%-56,7 \%$.

Larva ikan betutu yang diberi pakan rotifera yang diperkaya dengan klorella dan yang diperkaya dengan klorella + minyak jagung memberikan pertambahan bobot relatif yang rendah dibanding dengan pada perlakuan yang diperkaya dengan klorella + minyak ikan dan klorella + minyak ikan + minyak jagung. $\mathrm{Hal}$ ini diduga karena kandungan asam lemak omega 3 pada perlakuan pengkayaan dengan klorella dan pengkayaan klorella + minyak jagung lebih rendah dibanding pada perlakuan pengkayaan klorella + minyak ikan dan pengkayaan klorella + minyak ikan + minyak jagung, sebagaimana berdasarkan hasil analisis laboratorium dari keempat perlakuan dilaporkan bahwa kandungan asam lemak omega 6 dan omega $3(\%)$ dari setiap perlakuan sebagai berikut: Pengkayaan dengan klorella $=0,0146 \%$ dan $0,0351 \%$, pengkayaan dengan klorella + minyak ikan $=0,0088 \%$ dan $0,6124 \%$, pengkayaan dengan klorella + minyak jagung $=0,1799 \%$ dan $0,0351 \%$, pengkayaan dengan klorella + minyak ikan + minyak jagung $=0,1745 \%$ dan $0,3684 \%$. Perlakuan antara pengkayaan klorella + minyak ikan dan klorella + minyak ikan + minyak jagung tidak memberikan perbedaan yang nyata terhadap pertambahan bobot relatif larva. Kondisi ini memberikan gambaran bahwa larva betutu selain membutuhkan asam lemak omega 3, juga membutuhkan asam lemak omega 6 untuk mencapai pertumbuhannya. Tacon (1987) melaporkan

Tabel2. Pengamatan kualitas air selama penelitian

Table 2. Observation of water quality during experiment

\begin{tabular}{lc}
\hline \multicolumn{1}{c}{ Parameter (Parameters) } & Nilai (Value) \\
\hline Suhu (Temperature) $\left({ }^{\circ} \mathrm{C}\right)$ & $28-30$ \\
$\mathrm{pH}$ & $7.5-8.0$ \\
Oksigen terlarut (Dissolved oxygen) $(\mathrm{mg} / \mathrm{L})$ & $3.7-5.8$ \\
$\mathrm{NH}_{3}(\mathrm{mg} / \mathrm{L})$ & $0.013-0.028$ \\
$\mathrm{CO}_{2}(\mathrm{mg} / \mathrm{L})$ & $0.56-2.43$ \\
\hline
\end{tabular}


bahwa minyak nabati (kedelai) mengandung asam lemak essensial linoleat dan linolenat, sedang minyak ikan mengandung asam lemak esensial eikosapentaenoatacid (EPA) dan decosaheksaenoatacid (DHA). Asam-asam lemak ini penting untuk pertumbuhan (Kanazawa et al., 1979). Kekurangan asam lemak essensial dalam pakan larva dapat mengakibatkan pertumbuhan yang lambat dan meningkatkan angka kematian larva ikan (Purba, 1995).

Hasil pengamatan kualitas air selama penelitian masih dalam keadaan optimal untuk kehidupan ikan.

\section{KESIMPULAN}

Pertambahan bobot relatif larva ikan betutu yang tertinggi dicapai pada pengkayaan dengan klorella + minyak ikan dan pengkayaan dengan klorella + minyak ikan + minyak jagung.

Sintasan dan pertambahan panjang relatif larva ikan yang diberi pakan rotifera yang diperkaya dari keempat jenis perlakuan tidak memberikan perbedaan yang nyata $(P>0,05)$, dengan sintasan berkisar $1,2 \%-7,6 \%$.

\section{DAFTAR PUSTAKA}

Chuang, J.L. 1990. The nutrition of prawn. Ed. HoffmanLa Roche, F., Ltd. Vitamin and Fine Chemical Division Animal Nutrition and Health, Based Switzerland. $62 \mathrm{pp}$.

Effendi,M.I. 1978. Biologi Perikanan, Bag. I. Study Natural History. Fakultas Perikanan IPB. Bogor. 150 pp.

Faradia, Y. 1991. Respon Kelangsungan Hidup dan Pertumbuhan Benih Ikan Betutu (Oxyeleotris marmorata Blkr.) terhadap Berbagai Sumber Pro- tein Pakan dan Lingkungannya. Skripsi Fakultas Perikanan Universitas Padjajaran, Bandung. 54 pp.

Kanazawa, A., S. Tashima, K. Chalayondeja. 1979. Biosynthesis of fatty acid from acetat in the prawn, Penaeus Monodon and Panaeus Merguiensis. Mem. Fac. Fish. Kagoshima Univ. 28:21-26.

Kitajama, C., T. Tarakawa, S. Fujita. O. Imada, T. Watanabe, and Y.Yone. 1980. Dietary value for red sea bream larvae of rotifers, Brachionus plicatilis culture with a new type of yeast. Bull. Jap. Soc. Sci. Fish, 46 (1) : 43-45.

Kompiang, I.P. dan S. Ilyas, 1988. Nutrisi/udang relevansi untuk larva/induk. Prosiding Seminar Nasional Pembenihan Ikan dan Udang. Kerjasama Badan Litbang Pertanian dengan Universitas Padjajaran. Bandung. p.248-290.

Koren, W. M., G.W. Kissil, and A. Tandler, 1989. Lipid W3 Requirement of Sparus Aurasa larvae during starvation and feeding. Aquaculture, 79:185-91.

Purba,T. 1995 Peningkatan gizi rotifera pakan larva ikan kerapu macan. Warta Penelitian dan Pengembangan Pertanian. 17 (1):4-6.

Tacon, A. G.J. 1987. The Nutrition and Feeding of Farmed Fish and Shrimp. A training manual. 1. The essential nutrient. FAO of the United Nation. Field Document 2, GCP/RLA/075/1 TA. 25pp.

Tan, O.K.K and T.J. Lam 1973. Induced breeding and rearing of sand goby (Oxyeleotris marmorata Blkr.) fry. Aquaculture, $69: 299-306$.

Tavarutmaneegul, P. and C Kwei Lin. 1988. Breeding and rearing of and goby (Oxyeleotris marmorata Blkr.) fry. Aquaculture, $69: 299-305$.

Widiyati, A., dan H. Djajasewaka. 1992. Penelitian pakan buatan terhadap pertumbuhan dan kelangsungan hidup larva betutu (Oxyeleotris marmorata Blkr.) dalam lingkungan pemeliharaan suhu optimal. Pros. Sem. Has. Penel. Perik. Air Tawar, Balitkanwar, Bogor. p. $248-253$. 